\title{
Some Ideas About the Application of Internet of Things to Petroleum Engineering
}

\author{
Shiwen Chen ${ }^{1, a}$, Liming $\mathrm{Gu}^{2, \mathrm{~b}}$, Xin Zhang ${ }^{1, \mathrm{c}}$, Xishun Zhang ${ }^{1, \mathrm{~d}}$, Hongfei Wang ${ }^{3, \mathrm{e}}$, \\ Wei Tian ${ }^{4, f}$, Han Qin ${ }^{5,9}$ \\ ${ }^{1}$ Research Institute of Petroleum Exploration and Development, CNPC, Beijing \\ ${ }^{2}$ Development Department of Jidong Oilfield, CNPC, Hebei \\ ${ }^{3}$ RISE, CNPC, Beijing \\ ${ }^{4}$ Daqing Oilfield, Heilongjiang \\ ${ }^{5}$ Oil and Gas Engineering Research Institute, Tarim Oilfield, Korla, Xinjiang \\ a chensw_2016@163.com, ${ }^{b}$ guliming@petrochina.com.cn, ${ }^{c}$ zhangxin92@petrochina.com.cn, ${ }^{d}$ \\ zhangxishun@petrochina.com.cn, ${ }^{\mathrm{e}}$ wang-hongfei@cnpc.com.cn, ${ }^{\mathrm{f}}$ tianwei@petrochina.com.cn, ${ }^{9}$ \\ qh-tlm@petrochina.com.cn
}

Keywords: Internet; Intelligent; Petroleum Engineering; Digital; Application.

Abstract. As the third Information revolution after following computer and internet, the internet of things has been widely used in various fields. Petroleum industry is always supported by highly concentrated information technology. So the internet of things should be applied to it to solve some issues arising in the process of digital oilfield. Firstly, the paper presents some main problems faced by petroleum engineering and analyzes the importance of information technology played in reducing cost and increasing efficiency. Then, some successful projects having been applied in oilfield are introduced and the huge economic and management efficiency are analyzed. Finally, based on the need of information technology the paper presents some ideas about some applications of the internet of things to petroleum engineering. The ideas can be as reference or suggestion for the improvement of digital oilfield.

\section{Introduction}

Recently, with the improvement of information technology, many petroleum industries invest lots of funds to create digital and intelligent oilfields. ERP , GIS , MES and other information projects obtain the initial success. But, there are still many of issues faced by production and management ${ }^{[1]}$.

For oil and gas exploration area, the cable seismograph is dominant, which is too heavy and difficult to move. Also, the equipment has other disadvantages including long exploration cycle, limited road number, and high maintenance costs.

For well drilling area, there are many kinds of equipments which are mobile and dangerous and should be managed efficiently. Nowadays, various wired sensors are covered over all equipment, which need many of monitor unit. Additionally, it's difficult to layout the cables and to managed.

For oil and gas production area, most production and operation equipments are worked in field environment far from the production basis. Now, monitor units based wired sensors network are popular with many of oilfields. Many of issues are generated resulted from the cables. We should layout and bury the cables, which is expensive and unreliable. Also, it's need too many of RTU in well head used for data delivery, which result in a high cost.

\section{Application Status of the Internet of Things in Petroleum Engineering}

The Internet of Things. With the use of wireless sensor networks, real-time communication and the free exchange of information between users and the intelligent objects around them firmly leave the domain of science fiction, which is named Internet of Things ${ }^{[2]}$. 
The current Internet of Things was officially listed as national key strategic development of emerging industries. Internet of Things has a long industrial chain industry, involves a number of characteristics of industrial clusters, its scope of application covers almost all walks of life.

Internet of Things is currently one of the most potential industries, will greatly promote traditional industrial transformation and upgrading, leading the strategic development of emerging industries, to achieve economic structure and strategic adjustment, trigger mode of social production and economic development of the depth of change.

RFID is the most popular technology of Internet of Things, which is in use all around us. A basic RFID system consists of three components: An antenna or coil; A transceiver (with decoder); A transponder (RF tag) electronically programmed with unique information, as in fig. 1.
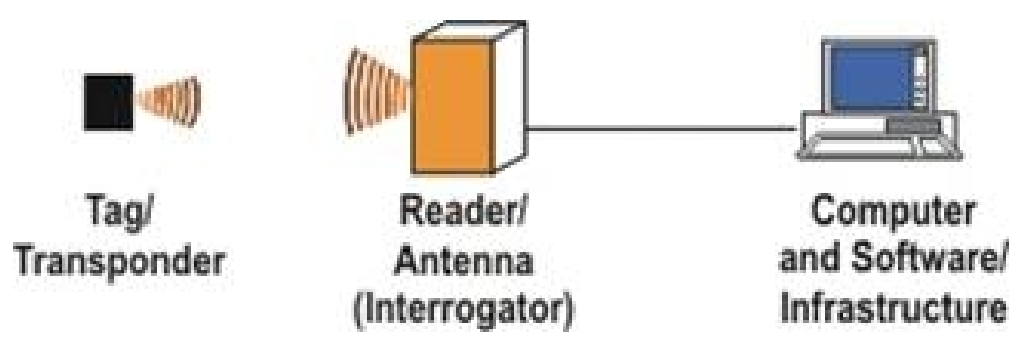

Fig. 1 The constitution of RFID

Application Status of the Internet of Things in Petroleum Engineering. The technology of Internet of Things having been used initially in some oilfield. The paper takes Huabei oilfield, Dagang oilfield and Changqing oilfield for examples.

Huabei oilfield installed many of RFID tags in the well heads, which can collect some key data of well production and send the data to the reader of RFID wirelessly. The operators of well can accept the real-time data of well by handheld reader, which help the managers to learn the working condition of well. Further, it can provide the function of pre-warning for some abnormal well ${ }^{[3]}$.

Dagang oilfield adopts RFID technology to manage well automatically. The oilfield installed RFID tags in indicator card test instrument, which can test real-time indicator card of well and send the data to computer. Then the computer analyzed the working condition of well real-timely.

Changqing oilfield installed many of CCD cameras in well site. So, every thing can be monitored by the cameras. The pictures are sent to the computers of offices. Operators can learn all things happened in well site. Also, managers can shout to the operators of well site to arrange task through the cameras. Because of the system, it's no longer afraid of things was stolen ${ }^{[4]}$.

Sulige gas field developed a set of remote distance intelligent open/shut in equipment for wells, which is a technique to adjust opening extent of valves by remote control(shown in Fig. 2). Instead of the original manual needle valve, an electric needle valve(shown in Fig. 3) which can self-control opening extent has been installed. This technology has realized imitate-artificial well opening and shutting in process via remote-controlling on high/low pressure well head, increasing work efficiency greatly. This technology is useful to raise the field fine management level, and has a great field application prospect in the future. 


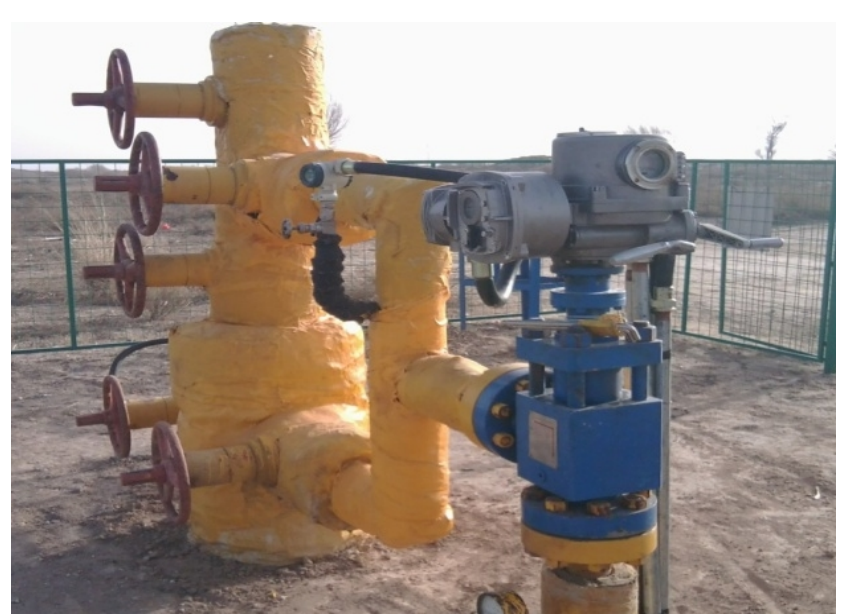

Fig. 2 Remote distance intelligent open/shut in equipment

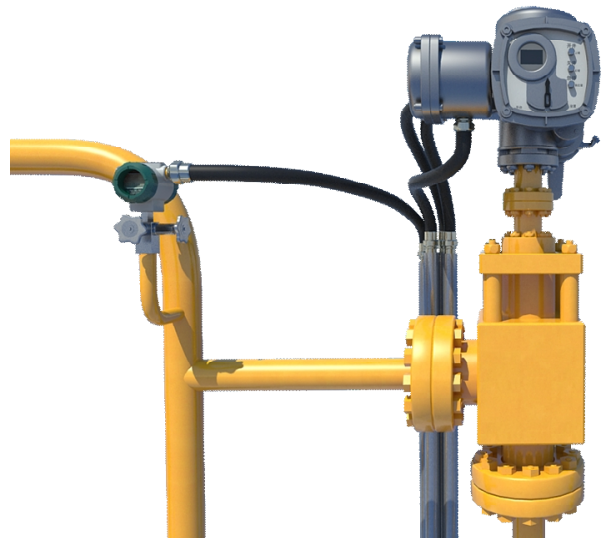

Fig. 3 Structure diagram of valve element

\section{Some Ideas About the Application of Internet of Things to Petroleum Engineering}

Intelligent Controlling System of Well Head or Offshore Oil Platform. It can avoid most of accidents by learning work conditioning of a well or an oil production petroleum. But well's work condition is judged by many data of a well. So, if we install RFID tag into well head equipment, the key data including tubing pressure, casing pressure, electric voltage, electric current, indicator card and so on. The data is sent through wireless method to computer or handheld reader. The data is analyzed by special software, which is based to judge well's work condition. If work condition is abnormal, then the handheld reader can send some instructions to the well likes closing the well, judge the working parameters etc.

Intelligent Controlling System of Downhole Equipment. With the improvement of intelligent well, many downhole equipment are installed in well. The fluid of downhole changes with time, so the production condition changes accordingly. The work condition of downhole equipments should be changed with the fluid condition. Taking segregated completion of horizontal well as example, many packers and throttle valves are installed in casing. With the production, some segments may be broken through by water, So, the throttle valves installed on these segments should be closed or turned down to reduce water's flux. If we install RFID tag into these downhole equipments, many important data like as pressure, flux, water cut can be tested real-timely and sent to ground computer. Through analyzing to the data, the breakthrough positions can be decided. So, we can send instructions to these packers or throttle valves to make them close or turn down.

Emergency Management System. Position information can be obtained by sensor network. ConocoPhillips company has a successful case of using the technology of Internet of Things. All 
operators on drilling tower have RFID cards, which can record operators' position information. So, the movement routine of all workers can be inspected from offshore to the drilling tower. When emergency accidence is happened, Search and rescue personnel can find the positions of disappeared persons. In China, the technology is applied in colliery.

\section{Conclusions}

(1) In information period, oilfield encounter many of issues, which can be solved by the technology of Internet of Things.

(2)Some successful projects having been applied in oilfield are introduced and the huge economic and management efficiency are analyzed.

(3)The paper presents some new ideas about some using of the Internet of Things to petroleum engineering. It will greatly promote petroleum industry and play an important role in reducing cost and increasing efficiency.

\section{Acknowledgements}

This work was supported by Research Institute of Petroleum Exploration and Development, CNPC.

\section{References}

[1] Niu Na, Internet of Things and Its Application to Petroleum Industry, China Computer \& Communication, 2010(9), 113.

[2] He Yi, Cao Banggong, Zhang Qinghe, Analysis About Application of Internet of Things to Petroleum Industry, Petroleum and Chemical Equipment, 2010(13), 13-16.

[3] Wu Zhenghong, The Widely Application of RFID to Petroleum and Petrochemical Fields, http://www.rfidworld.com.cn /2009.

[4] ConocoPhillips Applied RIPD Technology to Ensure Driller's Safety. http://www.rfi dinfo.com.cn /2008. 